\title{
La enfermedad mortal en Hermann Hesse y la literatura como una sanación simbólica y temporal
}

\section{Deadly disease in Hermann Hesse and literature as symbolic and temporal healing}

\author{
Mario Jhonatan Córdova Carruitero' \\ Universidad Nacional Mayor de San Marcos \\ mario.cordova@unmsm.edu.pe \\ ORCID 0000-0001-9184-0504
}

Citar como: Córdova, M. (2019). La enfermedad mortal en Hermann Hesse y la literatura como una sanación simbólica y temporal. Desde el Sur, 11(2), pp. 149-167.

\section{RESUMEN}

Entre 1915 y 1919, el escritor alemán Hermann Hesse sufrió una profunda etapa de crisis nerviosa. El trastorno psicológico desató en él una crisis existencial que lo llevó a replantearse cuestiones sobre el sentido de la vida. Esta dura etapa en su vida lo motivaría a acudir a tratamientos psicoterapéuticos con el psicoanalista J. B. Lang, discípulo del reconocido psicoanalista Carl Gustav Jung, quien años después sería el terapeuta de Hesse. La gran crisis del escritor y las terapias que recibió fueron la base para escribir Demian, obra literaria donde el escritor alemán puso de manifiesto todo el cataclismo interior que padeció en esa época. En el presente artículo se demostrará cómo los trastornos psicológicos que sufrió Hesse fueron un punto de quiebre para la creación de una obra de literatura que le sirvió como una especie de sanación simbólica y temporal.

1 Lima, 1991. Estudiante de la carrera de Literatura en la Facultad de Letras y Ciencias Humanas de la Universidad Nacional Mayor de San Marcos. Fundador y director del grupo de promoción cultura independiente Leitmotiv. Ha participado como ponente en el Congreso Internacional «Los mudos hablan» homenaje a Julio Ramón Ribeyro de 2019, organizado por la Academia Peruana de la Lengua, con la exposición «Los peruanismos en el cuento "El próximo mes me nivelo" de Julio Ramón Ribeyro». Asimismo, ha sido ponente en el Congreso Internacional de Literatura Hispanoamericana «Ricardo Palma», organizado por la Academia Ecuatoriana de la Lengua y la Academia Peruana de la Lengua, con el artículo «Voces andinas en "Palla-Huarcuna" de Ricardo Palma». Ambos artículos fueron publicados por la Academia Peruana de la Lengua. Del mismo modo, ha participado en el Congreso Internacional «Literatura y enfermedad», organizado por la Universidad Nacional Mayor de San Marcos y el Centro de Estudios Literarios Antonio Cornejo Polar (Celacp), con la exposición «La enfermedad mortal en Hermann Hesse y la literatura como una especie de sanación simbólica y temporal». 
Finalmente, quedará demostrado cómo estas enfermedades psicológicas muchas veces son las génesis fundamentales para la creación artística.

\section{PALABRAS CLAVE}

Hermann Hesse, trastorno psicológico, enfermedad mortal, literatura, sanación simbólica.

\section{ABSTRACT}

Between 1915 and 1919, the German writer Hermann Hesse would suffer a profound nervous breakdown. This psychological disorder would unleash in him an existential crisis that would lead to his rethinking of questions concerning the meaning of life. This difficult period in the life of Hermann Hesse led him to seek psychotherapeutic treatment with the psychoanalyst J. B. Lang, a disciple of the renowned psychoanalyst Carl Gustav Jung, who years later would become Hesse's therapist. The writer's major crisis and the therapies he received formed the basis for his book Demian. In this literary work, the German writer revealed the inner turmoil he had suffered. This article seeks to demonstrate how the psychological disorders suffered by the German writer Hermann Hesse formed the tipping point in the creation of a body of literature that functioned as a kind of symbolic and temporal healing balm. Finally, we will discuss the ways in which such psychological conditions often form the fundamental genesis of artistic creation.

\section{KEYWORDS}

Hermann Hesse, psychological disorder, deadly disease, literature, symbolic healing

\section{Introducción}

En una pequeña ciudad de Calw, en Wurttemberg —antiguo estado de Alemania-, en 1877, nació Hermann Hesse, escritor reconocido por obras como Demian, El lobo estepario, Siddhartha, El juego de los abalorios — publicada tres años antes de recibir el Premio Nobel en 1946-, Narciso y Golmundo, entre otras. Hesse, que lograría popularidad luego de la publicación de su novela Demian (1919), cuenta con una inmensa variedad de producciones literarias, desde sus primeros poemas en versos o sus relatos cortos, hasta sus novelas más trabajadas. En este sentido, es pertinente traer a colación lo que alguna vez señaló Francisco Miró Quesada: 
Hablar sobre Hermann Hesse es difícil, pues, como la mayor parte de los grandes escritores, tiene una obra que no solo es sumamente vasta, sino que es increíblemente variada. Es tan rica y variada que pueden encontrarse en ellas aspectos difíciles de interpretar, sutilezas que escapan al más penetrante análisis, y hasta pasajes contradictorios. Si la obra de los filósofos presenta dificultades al análisis interpretativo, es fácil imaginar las dificultades que han de presentar las creaciones de escritores como Hesse. El gran escritor es una fuerza desatada del espíritu que expresa en grandioso torbellino todas las emociones, pasiones, experiencias de que es capaz un ser humano, todos los afanes, ensueños, ideales, en una palabra, el conjunto inagotable de las posibilidades humanas. Es, pues, muy difícil orientarse en esta selva intrincada y tempestuosa de la gran obra literaria (Horia, 1976, p. 159).

Pues bien, tras un análisis exhaustivo de la obra literaria de Hesse, y teniendo en cuenta la advertencia de Francisco Miró Quesada, podemos lanzar la hipótesis de que esta, en su gran mayoría, aborda características que pertenecen tanto al romanticismo como al existencialismo. Al respecto, Hugo Ball señala que «Hermann Hesse es el último caballero de la estirpe esplendorosa del romanticismo» (2008, p. 25). Por otro lado, el escritor alemán fue un autor cuya importancia en la cultura alemana y occidental del siglo XX es innegable. Su nombre, con justa razón, figura en cualquier libro de historia de la literatura alemana junto al de otros autores reconocidos, como Rainer María Rilke, Thomas Mann, Bertolt Brecht, Heinrich Böll, entre otros.

Estos autores, marcados por la época de entreguerras, comparten temas comunes, como la muerte o la insatisfacción con la vida misma. Asíllegamos a la conclusión, como lo señala el crítico literario Theodor Ziolkowski (1976), de que Hesse fue un escritor que se sitúa entre el romanticismo y el existencialismo. De lo que no cabe duda es que el autor de Demian fue uno de los escritores más consagrados de la literatura del siglo XX.

Ahora bien, el camino de vida de Hermann Hesse no fue sencillo y durante muchos años tampoco fue inteligible. El autor alemán pasó por más de una crisis existencial durante sus años de vida. Sin embargo, si tenemos que hablar sobre su gran crisis, tendríamos que situarnos entre 1915 y $1919^{2}$. Este periodo en la vida del alemán sería importante por dos motivos: la crisis nerviosa por la que atravesó debido a la Primera Guerra Mundial y a los problemas personales, así como por la producción de la novela Demian. El mal por el que atravesó Hesse entre estos años lo

2 La gran mayoría de críticos, como quedará evidenciado en este artículo, coinciden en esta hipótesis. 
golpeó fuertemente, al punto de llevarlo a terapias psicoanalíticas, pero también lo ayudó a fomentar su personalidad. A su vez, ello lograría marcar un punto de quiebre en su producción literaria. Si tenemos en cuenta las primeras publicaciones de Hesse - Canciones románticas, Hermann Lauscher, Bajo la rueda, etc.- y las comparamos con las que vendrían después de la publicación de Demian - El lobo estepario, Siddhartha, EI juego de los abalorios, etc.- queda en evidencia la evolución del escritor de Calw.

El presente artículo demostrará cómo la crisis neurótica por la que atravesó Hesse, de 1915 a 1919, fueron un punto de quiebre en su producción literaria. Asimismo, quedará demostrado cómo la creación de la novela Demian sirvió como una especie de sanación simbólica y temporal al autor alemán.

\section{Metodología}

Para la creación del presente artículo se ha estudiado a profundidad la biografía de Hermann Hesse haciendo énfasis en el periodo de 1915 a 1919. Asimismo, se han estudiado los trastornos psicológicos por los que atravesó durante estos años, teniendo en cuenta dos puntos. En primer lugar, la neurosis - hoy llamado trastorno psicológico- que padeció Hesse fue tratada por el psicoanalista J. B. Lang, así que las terapias recibidas son producto del enfoque psicoanalítico de la escuela de Jung. En segundo lugar, no vamos a lanzar ningún diagnóstico con respecto a la crisis psicológica de Hesse. Es menester señalar que el presente artículo es escrito por un especialista en la literatura y no en el área de salud. Temiendo el error, muy común por parte de algunos de mis colegas, en juzgar tajantemente las personalidades de los escritores sin ser médicos psiquiátricos especializados en el tema, hago esta aclaración.

Por otro lado, debo mencionar que también han contribuido con el presente artículo libros de historia de la literatura alemana y de crítica e interpretación de las obras de Hermann Hesse, en especial los estudios en torno a la novela Demian. Ahora bien, cabe señalar que al momento de interpretar este libro, hemos seguido los puntos sostenidos por Mario Vargas Llosa en su texto Cartas a un joven novelista.

\section{Hermann Hesse y la crisis existencial}

Hermann Hesse, como ya se mencionó, pasó por más de una crisis psicológica en el transcurso de su vida y durante su carrera literaria. Afortunadamente, contamos con el diario de Marie Gundert-Dubois — su madre- para conocer los primeros años de vida del escritor alemán. Con respecto al nacimiento de Hesse, la madre escribe: 
El lunes, 2 de julio de 1877, después de un día pesado, Dios nos envió en su misericordia, a las siete y media de la tarde, al anhelado niño, un niño muy grande, pesado y guapo, que enseguida tuvo hambre. Dirige sus ojos azules a la luz y la busca volviendo a la cabeza; es una criatura espléndida, un bebe sano y fuerte. Escribo estoy hoy, 20 de julio, 18 días después. Gracias a Dios por toda su misericordia (2008, pp. 34-35) ${ }^{3}$.

La madre y el padre —Johannes Hesse- del escritor creían en el Dios cristiano y eran profundamente devotos, lo cual influyó de manera marcada en la formación de la personalidad del hijo.

En 1884, y como anticipación a su gran crisis, la madre escribe lo siguiente:

Hermann, cuya educación tantas angustias y esfuerzos nos causó, va ahora decididamente mejor. Del 21 de enero al 5 de julio (un semestre, pues) estuvo todo el tiempo en casa de los niños, y solo pasaba los domingos con nosotros. Se portó bien, pero volvió a casa pálido, delgado y cabizbajo... El efecto fue decididamente bueno y curativo [...] ahora es mucho más fácil de tratar. ¡Gracias a Dios! (2008, pp. 4445).

Es claro que ya se puede percibir la personalidad conflictiva del pequeño Hesse desde sus primeros años de vida. También podemos notar que los padres tuvieron dificultades durante la educación del escritor cuando era un niño de 7 años, y deducir los métodos religiosos que utilizaron para su crianza.

Asimismo, quedan evidenciadas las consecuencias (pálido, delgado, cabizbajo) que sufriría Hesse por sus problemas de comportamiento y que marcarían su futura condición física.

Los hechos transcurrieron con presunta normalidad durante los primeros años de vida del escritor hasta que llegó 1890. El padre de Hermann Hesse matriculó a su hijo en la escuela latina Göppingen, para que el niño empezara con la carrera de Teología, siguiendo la tradición de su familia. No obstante, el pequeño Hermann Hesse no estaba destinado para ese camino. $\mathrm{O}$, en todo caso, el escritor no lo quiso así. Ya con 13 años, tomó una decisión — según el propio Hesse, la más importante de su vida- que lo marcaría por siempre: «quería ser poeta o nada». Al respecto, Hesse escribió:

La situación era así: desde los 13 años tuve clara una cosa: o sería poeta o no sería absolutamente nada. Pero a esta evidencia se fue

3 Para los datos del diario de la madre de Hermann Hesse hemos utilizado el libro Hermann Hesse. Su vida y su obra (2008), de Hugo Ball. 
sumando gradualmente otra persona circunstancia. Era posible llegar a ser profesor, pastor, médico, artesano, comerciante, cartero, también músico, pintor o arquitecto. Todas las profesiones del mundo tenían su vía de acceso, sus condiciones, una escuela, unas clases de iniciación para el principiante. ¡Solo el poeta no contaba con nada de eso! Estaba permitido e incluso se consideraba un honor que alguien fuese poeta: es decir, que tuviera éxito y fuera conocido como poeta, lo cual, por desgracia, generalmente sucedía cuando la persona ya estaba muerta. Pero convertirse en poeta era una cosa imposible; quererlo ser, una ridiculez y una infamia, según pronto experimenté (Michels, 1977, pp. 10-11).

Hesse tuvo conciencia de sus conflictos internos a los 13 años. Su enfermedad mortal ${ }^{4}$ —en términos de Kierkegaard-se agudizó tras su decisión de 1890. Sus padres querían que se dedicara a la teología, pero el pequeño deseaba no solo no ser teólogo, sino ser un poeta.

Es entendible el conflicto por el que atravesó toda la familia en este periodo. El problema se agravó cuando Hesse se escapó del monasterio de Maulbronn, dejando atrás los planes teológicos de sus padres para con él. El escritor nos cuenta lo ocurrido en su diario de $1925^{5}$ :

Cuando tenía 13 años y acaba de iniciarse el conflicto, mi comportamiento en casa de mis padres y también en la escuela comenzó a dejar tanto que desear que fui desterrado al colegio latino de otra ciudad. Un año más tarde pasé a ser pupilo de un seminario de teología, aprendí a escribir el alfabeto hebreo y ya no me faltaba mucho para comprender qué es una dagesch forte implicitum cuando de pronto se desencadenó dentro de mí una tormenta que me llevó a huir de la escuela monástica, a ser castigado con una pena de reclusión rigurosa en la cárcel universitaria y a ser expulsado del seminario (Michels, 1977 , pp. 11-12).

Esta etapa en su vida - que el escritor describió en novelas como Bajo la rueda - fue dura y difícil para el adolescente alemán, que no solo desobedecía a las órdenes de sus padres, sino que tenía el objetivo - por el cual era capaz de dejarlo todo- de ser escritor; tarea difícil y hasta soñadora.

Hesse experimentaba aquella tormenta interior que no lo dejaría tranquilo durante muchos años:

4 Para Kierkegaard, la enfermedad mortal es la desesperación (se hace referencia al libro La enfermedad mortal, de 1849).

5 El diario de Hesse termina con una historia de ficción. No obstante, en comparación con la biografía de su vida escrita por otros autores, lo que Hesse cuenta en ese texto, desde su nacimiento hasta 1925, es totalmente verídico. 
Pasé entonces un tiempo esforzándome por sacar adelante mis estudios en un gimnasio, pero también aquello acabó en cárcel universitaria y expulsión. Luego fui aprendiz de tendero, durante tres días, volví a escaparme y desaparecí algunos días y noches con grandes preocupaciones de mis padres. Pasé medio año como ayudante de mi padre, trabajé otros seis meses como meritorio en un taller mecánico y fábrica de relojes de campamento [...] para abreviar: durante más de cuatro años todo lo que intentaron hacer conmigo resultó un rotundo fracaso, en ninguna escuela me querían, no duraba mucho en ningún aprendizaje. Cada tentativa de hacer de mí un hombre acabó en un fracaso (Michels, 1977 , p. 12).

El escritor dejó documentado, tanto en su diario, como en distintas cartas y en diferentes obras literarias, sus crisis psicológicas y existenciales de sus primeros años de vida. Al respecto, el biógrafo Hugo Ball señala:

Es característico de Hesse haber documentado cada paso de su vida, haber extraído su obra literaria y poética solo de su andadura, de sus observaciones y experiencias [...] Esta forma de creación, que toma como punto de partida las peculiares circunstancias de Hesse, tiene en él consecuencias del todo inusuales. Por mencionar tan solo algunas: no se puede encontrar fácilmente, en el ámbito de la literatura actual, un poeta que sepa tanto de sí mismo y de las cosas con las que tiene que vérselas $(2008$, p. 47).

Pero hasta el camino más difícil y oscuro se puede volver algún día claro e inteligible. Si debemos destacar algo de todo este tiempo en el que Hesse padeció «la enfermedad mortal», es que el autor de la novela Demian estuvo seguro de una decisión: «ser poeta». Ante eso, las distintas circunstancias de la vida pueden conducirse un poco menos difícil.

De 1895 a 1898, Hesse fue aprendiz de un librero y así se rodeó de lo que más le gustaba. Aunque esta situación tampoco lo tuvo satisfecho, contribuyó en su formación de escritor. En 1899, con 22 años, hizo su primera publicación en forma de libro, Canciones románticas. Hesse, por fin, podía sentir de cerca lo que era ser un poeta. En 1901 publicó Hermann Lauschery, en 1903, Peter Camenzind, su primera novela.

Hesse ganaba una fama regular. La aparente tranquilidad llegaría a su vida.

\section{Análisis de la gran crisis}

En 1914 estalló la Primera Guerra Mundial y, junta a ella, la crisis psicológica de Hesse. Mucha importancia en ella tuvieron también los asuntos de su familia y de su mundo interior. 


\section{Contexto social}

Hesse se presentó como voluntario de la Gran Guerra. Con más dudas que certezas, apoyó al país que lo vio nacer. Al respecto, podemos traer a colación lo que escribe Hugo Ball: «Al estallar la Primera Guerra Mundial, en 1914, Hesse se encuentra en un estado espiritual poco propicio, como cabe suponer a los entusiasmos patrióticos» (2008, p. 125).

Hesse no fue aceptado debido a su baja condición física. Sin embargo, en 1915 se le asignó a la legación alemana en Berna, donde trabajó para el Servicio de Atención a los Prisioneros de Guerra Alemanes y procuró lectura a los cientos de prisioneros de guerra. El biógrafo Hugo Ball relata:

Cuando llegó la guerra, se puso a disposición del consulado competente. Dado que, en calidad de medio suizo y con sus múltiples relaciones con influyentes familias del país, parecía una final adquisición, se le asignó en principio al servicio civil en la legación de Berna [...] Hesse organizó un departamento de carácter extraterritorial para facilitar a los presos de guerra alemanes literatura en su lengua; una fundación que se mantuvo hasta el término de la guerra y que, al final, estaba de tal modo extendida que cientos de miles de trabajadores, estudiantes, funcionarios e incluso eruditos caídos en prisión estaba suficientemente abastecidos de conocimiento y entretenimientos (2008, p. 134).

Como ya se mencionó, Hesse documentaba todo lo que le ocurría. La Primera Guerra Mundial no fue la excepción:

Entonces llegó aquel verano de 1914, y de pronto todo apareció completamente transformado por dentro y por fuera. Quedó de manifiesto que nuestra anterior prosperidad se erigía sobre terreno inseguro, y así comenzaron los malos tiempos, la gran escuela. Había empezado la llamada época gloriosa y no puedo decir que me encontrase mejor preparado, con más méritos ni hecho una persona mejor que las demás. Lo único que me diferenciaba de otros era que carecía de un gran consuelo que solazaba a tantos: el entusiasmo. Debido a ellos volví a encerrarme en mí mismo y entré en conflicto con el mundo circundante, me llevaron otra vez a la escuela, tuve que volver a desaprender al arte de vivir en paz conmigo mismo y con el mundo, y solo después de esta experiencia llegué a cruzar el umbral de iniciación en la vida (Michels, 1977 , pp. 13-14).

El caos y el desorden volverían a despertarse en Hesse. Con el estallido de la Gran Guerra, «la enfermedad mortal» del escritor alemán se hizo consciente.

Posiblemente el vivir de cerca las consecuencias de la guerra hizo que se mantuviera tajantemente en su contra: 
Jamás he olvidado una pequeña experiencia del primer año de guerra. Había ido a visitar un gran hospital en busca de una oportunidad de adaptarme, de un modo u otro, al mundo transformado, presentándome como voluntario, lo que en aquel entonces aún me parecía posible. En ese hospital de campaña conocí a una vieja señorita que antes había vivido con holgura de sus rentas y que ahora trabajaba allí como enfermera. Me contó con conmovedora convicción cuán feliz y orgullosa se sentía de haber podido vivir esa época gloriosa. Me pareció comprensible, pues esa señorita había necesitado la guerra para pasar de su inerte y absolutamente egoísta vida de solterona a una existencia activa y útil. Pero mientras me comunicaba su satisfacción en un pasillo lleno de soldados heridos y mutilados, entre salas atestadas de amputados y moribundos, se me retorcía el corazón. Por mucho que comprendía el entusiasmo de esa solterona, no podía compartirlo, no podía aprobarlo. Incluso 10 heridos por cada enfermera entusiasmada como esa era un precio demasiado caro a pagar por la satisfacción de esas señoras (Michels, 1977 , p. 14).

La Primera Guerra Mundial trajo muchas consecuencias fatales y funestas para el mundo y Hesse así lo entendería desde inicios de 1914. No solo no encajaba con el «entusiasmo» de sus compatriotas por la guerra, sino que sufriría ella. Su crisis psicológica se iba agudizando.

Al respecto, es pertinente traer a colación un fragmento de la carta que Sigmund Freud le escribió a Albert Einstein sobre la Primera Guerra Mundial:

¿Por qué nos indignamos tanto contra la guerra, usted, y yo, y tantos otros? ¿Por qué no la aceptamos como una más entre las muchas dolorosas miserias de la vida? Parece natural; biológicamente bien fundada; prácticamente casi inevitable. La respuesta es que todo hombre tiene derecho a su propia vida, que la guerra destruye vidas humanas llenas de esperanzas; coloca al individuo en situaciones denigrantes, lo obliga a matar a otros, cosa que no quiere hacer; destruye costosos valores materiales, productos del trabajo humano, y mucho más... Todo eso es verdad, y parece tan innegable que uno se asombra al observar que las guerras aún no han sido condenadas por el consejo general de todos los hombres (Ángel, Manuel y Ramón, 2007, p. 126).

En consecuencia, como podemos ver en lo expuesto por Freud, la guerra trajo consigo las más grandes situaciones denigrantes de los seres humanos. Todo ello hacía sufrir a Hesse, quien, a diferencia de Freud, no podía simplemente aceptar la guerra:

No, no podía compartir el entusiasmo por la época gloriosa, y así sucedió que la guerra me hizo sentir lastimosamente desde el principio, y durante años luché anonadado contra una desgracia en apariencia 
venida de fuera y caída del cielo, mientras a mi alrededor todo el mundo actuaba como si precisamente esa misma desgracia los llenara de entusiasmo. Y los artículos de los escritores, que descubrían la bendición de la guerra, y los llamamientos de los profesores y los poemas de guerra salidos de los estudios de poetas famosos, me hacían sentirme aún más miserable (Michels, 1977, pp. 14-15).

En su diario, Hesse escribe: «luché anonadado contra una desgracia en apariencia venida de fuera y caída del cielo». Es decir, la desgracia no provenía totalmente del exterior en Hesse. La Primera Guerra Mundial no fue lo único que alteró su crisis psicológica. La guerra lo afectó profundamente, pero también ocurrieron otras situaciones, de carácter interno, que lo afectaron de igual manera.

\section{La literatura en la época de la gran crisis de Hesse}

A inicios del siglo XX la literatura empezaría a optar por caminos distintos con respecto al siglo anterior. Los autores más leídos eran Fedor Dostoievski y Friedrich Nietzsche. Incluso algunos críticos literarios consideraban a estos dos autores como los grandes profetas de la Primera Guerra Mundial: «Nietzsche y Dostoievski habían anunciado el desastre con una sombrosa clarividencia» (Horia, 1976, p. 23). En Alemania también ocurriría un cambio sustancial con respecto a la literatura del siglo XX. Al respecto, Rodolfo E. Modern señala:

Desde 1809 hasta 1914 los distintos movimientos habían tentado nuevos caminos, y en el drama, la lírica o la novela los grandes creadores venían señalando, con esperanza o temor, el final de una época, en tantos aspectos magnífica. En este sentido, a partir de la sociedad o desde el fondo del individuo, coincidían los mensajes de Rilke y Hauptmann, de George, Hesse y Thomas Mann, de Hofmannsthal y Musil. La crisis del espíritu era una realidad cuya negación resultaba absurda, pero todo esto sería barrido por los cañonazos de la Primera Guerra Mundial, y correspondía otra vez a la literatura ser luz y testimonio, al mismo tiempo (1995, p. 300).

Por lo tanto, empezaba aparecer una literatura diferente, una más comprometida con lo que ocurría en la época y el nombre de Hermann Hesse, junto al de otros, aparecía un autor que rechazaba la guerra.

Uno de los movimientos que aparecieron durante esta época en Alemania fue el expresionismo. Al propósito, podemos citar lo dicho por Rodolfo E. Modern:

El expresionismo se constituyó así en un torbellino de fuerzas irresistibles, pero su misma violencia produjo el decaimiento final. Algunos de sus valores fueron episódicos, otros están incorporados a la gran literatura de nuestro siglo, pero conviene hacer notar que los 
grandes autores [...] cuya obra había sido ya comenzada en la última década del siglo XIX, siguieron su propio rumbo sin dejarse atraer demasiado por la novedad expresionista. Esto también vale, entre otros, para Rilke, Hesse, George, Thomas Mann, Hauptmann y Hofmannsthal (1995, p. 302).

Como ya dijimos, el nombre de Hesse aparece en cualquier libro sobre literatura alemana. Asimismo, se le relaciona con un espíritu independiente que se rebeló no solo contra la Primera Guerra Mundial, sino también contra la literatura de su época.

Durante estos años, Hesse publicó artículos contra la guerra, lo que generaría un gran rechazo por parte de sus compatriotas. Al respecto, Hugo Ball señala lo siguiente:

Si se tiene en cuenta su repercusión, la peor experiencia de aquella época fue indiscutiblemente la que tuvo con la prensa. Se estará tentado de decir que solo era la ambición ofendida de alguien anteriormente mimado la que era incapaz de acomodarse al tono más áspero de los cañones bélicos. Pero sin duda era algo más. Era la experiencia del poeta de que, ciertamente, se le había leído, pero se le había leído con ojos vidriosos. Era la decepción de que esa nación musical no era fiel ni a su propio ni dulce carácter ni a sus poetas. $Y$ era, además, una prueba de que se había construido en terreno seguro, de que se habían hecho nudos con hilos que no resistían una prueba de fuerza. Todavía en El lobo estepario, una década después, Hesse no había olvidado los insultos. No merecería la pena hablar de ellos, si no fuera porque para el poeta se convirtieron en punto de partida de una nueva y más desengañada estética (2008, p. 135).

Este rechazo que experimentó Hermann Hesse por parte de la prensa, y también por gran parte de sus amigos, agudizarían más aún la crisis psicológica del escritor alemán:

Aunque Hesse había estado viviendo en Suiza desde 1912, se consideraba aún alemán (y de hecho no se convirtió en ciudadano suizo sino hasta 1923). Había supuesto que entre él y sus lectores existía un sentido de compresión y solidaridad, pero la violenta reacción del público ante sus ensayos pacifistas de 1914 y 1915 demostraron cuán errónea era tal suposición. Se cancelaron suscripciones, hubo vendedores que se negaron a llevar sus libros, en la prensa alemana se le tildó de traidor, comenzó a llegarle el río de cartas ponzoñosas a través de la frontera, e incluso viejos «amigos» de Alemania cortaron relación con «la víbora que habían alimentado en su seno» (Ziolkowski, 1976, p. 15).

Hesse se sentía solo, en discordancia con el mundo que lo rodeaba. No se sentía entusiasmado por la guerra. Pensaba que su producción literaria no iba en concordancia con lo que sentía dentro de sí. 


\section{Los golpes familiares}

No solo la Primera Guerra Mundial y su relación con la prensa y muchos de sus colegas agudizaron la crisis psicológica de Hesse. Los problemas de índole familiar terminaron por hacer estallar su gran crisis. Es muy pertinente mencionar lo que diría su biógrafo: «Ya he dicho que solo hacía falta un insignificante empujón para que la precaria situación de Hesse entrara en crisis» $(2008$, p. 136).

Este suceso ocurriría alrededor de 1916, con tres sucesos que lo marcarían por siempre: el fallecimiento de su padre Johannes Hesse, la grave enfermedad de su menor hijo Martín, y los desórdenes psicológicos de su esposa. Estos tres hechos, sumados a la Primera Guerra Mundial, hicieron detonar en Hermann Hesse la gran crisis psicológica. Hugo Ball señala: «El motivo lo dio una sorprendente enfermedad de su hijo menor, Martin, nacido poco antes del viaje a La India. [...] Bien, este tierno Martin, el pequeño de Hesse, cae enfermo con síntomas que despiertan los peores temores» $(2008$, p. 136).

Los desastres de la Gran Guerra se trasladaron al hogar de Hesse. El escritor alemán entraría en un cuadro muy crítico. Ziolkowski sostiene:

En 1916 una serie de golpes personales resquebrajaron esta obligada compostura. Primero murió su padre. Su hijo menor, Martin, enfermó gravemente durante más de un año, precisamente por la época en la que el desquiciamiento mental de su esposa hizo necesario el internamiento, por un tiempo, en un sanatorio. Estas calamidades, aunadas a los efectos de la guerra, llevaron a Hesse tan cerca del colapso nervioso $(1976$, p. 16).

\section{Conflicto interior}

De esta manera, estallaría la gran crisis por la que atravesó el escritor alemán de 1915 a 1919. Hesse se encontraba en una situación muy complicada y delicada. Su vida perdía sentido. Al parecer, en lo último que pensaba era en ser poeta. Hesse veía cómo la vida se le estaba escapando. El camino, que se había vuelto inteligible, ahora resultaba incomprensible y difícil. Al respecto de todo lo sucedido, el propio escritor escribiría en su diario lo siguiente:

Cuando la nueva transformación comenzó a manifestarse en mis escritos y en mi vida, muchos de mis amigos volvieron a mover la cabeza. También fueron muchos los que me dejaron. Ello formaba parte del nuevo marco de mi vida, al igual que la pérdida de mi casa, mi familia y otros bienes y comodidades. Fue una época en la que a diario me desprendía de algo y a diario me sorprendía haber podido soportar también eso y seguir viviendo a pesar de todo, y seguir 
amando a pesar de todo alguna cosa de esa curiosa vida que solo parecía aportarme dolor, desengaño y pérdidas (Michels, 1977, p. 7).

Hesse se sentía cansado de la vida. Era como si, parafraseando lo dicho por Albert Camus, la vida lo hubiese sobrepasado. En 1916, decide marcharse y dejar de lado todo. Viaja a Lucerna; para ser más específicos, al balneario de Sonnmatt.

\section{Las terapias psicoanalíticas}

En 1916 Hesse visita a un joven médico, J. B Lang, quien fue discípulo de Carl Jung, para tratar su gran crisis.

Lang contaba entonces con 35 años y, por lo que dicen los biógrafos, entabló amistad rápidamente con Hesse. Según Hugo Ball: «El amigo que lo ayudó en muchos trechos fue el mencionado médico» (2008, p. 138). Hesse encontró a este médico que provenía de la escuela psicoanalítica y que se presentaba como la ayuda adecuada.

Las terapias que recibió Hesse fueron anotadas por el médico en algún cuaderno que imaginamos llevaba siempre consigo. Hemos tenido acceso a él gracias a la oportuna ayuda del biógrafo Hugo Ball, amigo íntimo del escritor y que documentó el tratamiento en el libro Hermann Hesse. Su vida y su obra.

En mayo de 1916 Hesse asistió a 12 sesiones analíticas con el doctor Lang. Algunos encuentros tuvieron lugar en Sonnmatt y otros, en Lucerna. Un mes después, en junio de 1916, el escritor se retiró del sanatorio y regresó a Berna. No obstante, las visitas al médico eran cada vez más frecuentes y algunas terapias duraban hasta tres horas. En el cuaderno de anotaciones de Lang, se registran 60 sesiones más, de junio de 1916 a noviembre de 1917. Es decir, Hesse acudiría, a raíz de la gran crisis, a más de un año de terapia psicoanalítica con el doctor Lang.

Ahora bien, si queremos conocer de qué trataban las terapias, es necesario traer a colación lo escrito por Hugo Ball:

No es posible imaginar un verdadero «tratamiento» en el intenso intercambio de dos hombres. Nada sería más errado. En la época de Gertrudis ${ }^{6}$, Hesse bien podía hacer un diagnóstico al propio médico. Sin duda era superior a su interlocutor de Lucerna en cuanto a dialéctica y formulación verbal. Tampoco los escritos de los primeros psicoanalíticos (Freud, Jung, Bleuler, Stekel) le eran ya ajenos: entretanto, precisamente Suiza se había convertido en uno de los centros de la teoría psiquiátrica (2008, pp. 139-140).

6 Novela de Hesse publicada en 1910. 
Lo que contribuyó a solucionar la gran crisis de Hesse fue una enseñanza de carácter moral. Hugo Ball señala:

Lo que el doctor Lang le aportó fue, con total independencia del conocimiento médico, una información vital; fue por primera vez una filosofía y forma de vida actual, fantástica. Pero sobre todo fue, como correspondía al origen católico, un estricto rechazo de la autoabsolución. [...] la convicción de que el individuo llevaba en sí mismo la explicación y la culpa de todos los acontecimientos de la vida exterior (2008, p. 140).

Hesse entendería, a raíz de las terapias psicoanalíticas, que la crisis por la que atravesaba, más que ser un asunto externo, era un suceso de su propio mundo interior: "se percató luego de que el desorden no estaba solo en el mundo, sino también dentro de él mismo» (Ziolkowski, 1976, p. 17). Es decir, aquellos hechos que ocurrían en el exterior -la Primera Guerra Mundial, la enfermedad de su hijo menor y los desórdenes psicológicos de su esposa - contribuían de manera profunda en la crisis de Hesse. Aquello era innegable, pero el verdadero origen de todo el mal psíquico se encontraba en su propia persona. El propio Hesse reflexionaría sobre este punto:

El fin de la guerra coincidió también con la conclusión de mi transformación y la culminación de los sufrimientos que me habían puesto a prueba. Estos sufrimientos ya nada tenían que ver con la guerra y el destino del mundo, y la derrota de Alemania, que en el extranjero anticipábamos con certeza desde hacía dos años, perdió asimismo al instante todo aspecto terrible. Estaba completamente inmerso en mí mismo y mi propio destino, si bien a veces tenía la sensación de que, en suma, se trataba de todo aquello en lo que no intervenían los hombres. Reencontré en mí toda la guerra y toda la sed de sangre del mundo, toda su irreflexión, toda su cruda avidez, toda su cobardía [...] solo tenía que observar el caos hasta el fin, con la esperanza, a veces viva, a veces tenue de encontrar al otro lado del caos la naturaleza, la inocencia (Michels, 1977, pp. 17-18).

Por lo demás, Hermann Hesse volvía a encontrar tranquilidad gracias al doctor Lang. El escritor pondría en manifiesto, en sus posteriores obras literarias, todo aquello que le sirvió para encontrar una solución a su etapa de crisis.

\section{La literatura como una sanación simbólica y temporal}

En 1919, Hesse publicó Demian, novela en la que plasmó su gran crisis de 1915-1919. La firmó con el seudónimo de Emil Sinclair. 
Sinclair fue el seudónimo que elegí, en la época de prueba más amarga de mi vida, para algunos de mis ensayos escritos durante la guerra de 1914 y luego para el Demian, pensando en el amigo y benefactor de Hölderlin en Homburg, cuyo nombre me era querido desde joven, que poseía para mí una magia secreta. Bajo el signo de Sinclair se halla para mí, aún hoy, aquella época cadente, la agonía de un mundo hermoso e irrecuperable, el despertar, en un principio doloroso, después aceptado plenamente, a una nueva compresión del mundo y de la realidad, el descubrimiento súbito de la unidad bajo el signo de la polaridad, de la coincidencia de los antagonismos, tal como los maestros del ZEN la trataron de traducir a fórmulas mágicas hace miles de años en China (Hesse, 1983, p. 38).

El motivo del seudónimo fue que, según Hesse, en 1919 empezó un nuevo inicio en su vida: «solo después de esta experiencia llegué a cruzar el umbral de iniciación en la vida» (Michels, 1977, p. 14). Hesse volvía a nacer. Ziolkowski señala lo siguiente:

Hesse se ha referido a esto como un tiempo de despedida cotidiana. Había dejado a su esposa y su familia, su hogar, su cómoda existencia, su reputación popular, toda su reserva de ideas livianas -y su nombre-. Pues el nombre de Hermann Hesse iba asociado con todos los viejos valores que sus nuevos compromisos le habían obligado a descartar. Para ser absolutamente leal consigo mismo había de tener un nombre nuevo para el hombre nuevo. Eligió Emil Sinclair, que apareció en la portada del Demian cuando fue publicado en 1919. Hesse lo usó como seudónimo para varios importantes ensayos que escribió entre 1917 y 1920 (1976, pp. 20-21).

La novela Demian ganó el premio Fontane y, por ello, el nombre del autor de la obra se tuvo que revelar.

Demian cuenta con una introducción y siete capítulos. El narrador es el protagonista, es decir, en la novela aparece el narrador-protagonista. El espacio se encuentra en primera persona. En cuanto al tiempo, este se desarrolla en el pasado. El narrador-protagonista nos cuenta una historia que ocurrió cuando era un niño y termina cuando este es un adolescente. Finalmente, el nivel de realidad de Demian está situado en un mundo realista.

Con Demian, Hermann Hesse puso en manifiesto su gran crisis psicológica. El pequeño Sinclair, narrador-protagonista de la novela, se encuentra en un mundo lleno de paz y tranquilidad, cuando de pronto es consciente de que existe un mundo opuesto a donde vivía. Sinclair ingresó a este mundo por culpa de una mentira que le hizo a Franz Kromer y de la cual este brabucón se aprovechó. La calma llegó a Sinclair cuando apareció un joven desconocido y misterioso que lo salvó de las penalidades que le hacía pasar Kromer. Este joven se llamaba Demian y se convirtió en su guía espiritual. El 
protagonista no tardó en darse cuenta de que su mal no se encontraba solamente en Franz Kromer, ni en Demian, ni en su familia, ni en la guerra: el origen de toda su crisis existencial también estaba dentro de sí mismo. Cuando Sinclair rompió el cascarón y aceptó que en su propio interior se encontraba tanto lo bueno como lo malo - este dualismo es representado en la novela por el dios Abraxas - , puede formar su personalidad. Demian se despide de Sinclair - ambos se encuentran luchando en la guerra- dándole un beso y diciéndole que desde ahora lo encontrará en su interior. Al respecto de la novela Demian, Hugo Ball señala: «Demian es, en toda regla, una eclosión del poeta; una eclosión hacia sí mismo, hasta un entrelazamiento primigenio» (2008, p. 143). Por su parte, el escritor Thomas Mann afirma:

Siendo «alemán», no es provinciano. Inolvidable el efecto electrizante que tuvo inmediatamente después de la Primera Guerra Mundial el Demian de aquel misterioso Sinclair, una obra que con impresionante precisión dio en el nervio de la época y arrastró a un entusiasmo agradecido a toda una juventud, que creía que de sus filas había surgido un portavoz de su sentir más profundo (y era un hombre de 42 años el que le daba lo que necesitaba) (Hesse, 1983, p. 37).

Cabe mencionar que en Demian el personaje Pistorius — un pianista solitario a quien conoce Sinclair - está inspirado en la figura del psicoanalista de Hesse, J. B. Lang.

La novela tuvo un gran éxito. Hesse se ganó, a partir de la publicación de esta obra, un nombre respetado dentro de la literatura universal. La paz, aquello que buscaba tan frenéticamente Hesse, por fin llegaba a su vida. O al menos así lo sentía. Por fin había terminado la etapa de la gran crisis: «El fin de la guerra coincidió también con la conclusión de mi transformación y la culminación de los sufrimientos que me habían puesto a prueba» (Michels, 1977, p. 17).

La producción de la novela Demian sirvió a Hesse como una especie de catarsis, entendido este término como «un proceso de liberación de los instintos innatos en el hombre y que a través de la escritura se puede producir una sublimación de las pulsiones insatisfechas o reprimidas» (Bobes, Baamonde, Cueto, Marful y Frechilla, 1995, p. 137). La novela dio una liberación a sus crisis nerviosas. En consecuencia, queda demostrado que la creación de Demian, junto a las terapias psicoanalíticas que recibió del doctor J. B. Lang, sirvieron a Hesse como una sanación simbólica y temporal.

\section{Conclusiones}

Una de las virtudes literarias de Hesse fue plasmar temas universales en su obra literaria. La condición humana abarca toda su producción. Sobre este punto, David Sobrevilla sostiene: 
Sus tesis están siempre implícitas en su expresión artística, [la] condición humana, [la] angustia que plantea el hombre a su finitud, el ser un ente que tiene deseo de infinito de vida eterna, sobre todo de vida plena, pero tiene que vivir en forma limitada, totalmente restringida por las circunstancias, por las contingencias, por los embates de la existencia. Y por eso, enfrentando a este problema, trata de encontrar salidas. La obra literaria de Hesse es una constante búsqueda, una constante marcha hacia las posibles salidas de los problemas que plantea la condición humana. El punto de partida es el problema que es para toda su propia vida (1977, p. 160).

Asimismo, las crisis nerviosas por las que pasó Hesse de 1915 a 1919, como ha quedado demostrado en el presente artículo, sirvieron como punto de partida en su producción literaria. El camino no fue fácil. Hesse se tuvo que alejar de su familia, de sus amigos y de sus inicios. Pero el producto de todo este cataclismo interior es Demian: «este último surgió en 1917 con verdadera vehemencia, como casi todas las obras del autor. El libro quedó escrito al cabo de unos pocos y ardientes meses» (2008, p. 141).

Y fueron aquellos ardientes meses lo que llevó a Hesse a ingresar directamente al mundo del psicoanálisis. Ya hemos hablado de la importancia que tuvo el doctor Lang en la vida del escritor alemán. No obstante, es importante traer a colación lo dicho por el crítico literario Zolkowski:

El psicoanálisis alteró la vida y la obra de Hesse. Le permitió entenderse a sí mismo más plenamente que nunca, mirar en el hondo del propio corazón y reconocer su propia culpa en el mal que había caído sobre él y el mundo. Y esto se reflejó directa e indirectamente en los libros que escribió desde este punto en adelante. No obstante, sería un error interpretar las obras ulteriores de Hesse de modo parcial desde el punto de vista psicológico. [...] «recibí entonces una agradable impresión de él, pero comencé en aquel tiempo a percatarme de que, para los analistas, una relación genuina con el arte es inalcanzable; carecen del órgano para ello». [...] A Hesse, según él mismo lo reconoció, le fue provechoso el estímulo de Jung y Lang, pero dejó asimismo en claro que sus metas trascendían el psicoanálisis. Aprovechó sus experiencias sobre el psicoanálisis siempre que fuese compatible dentro del marco general de su novela (Demian, por ejemplo), pero, en su concepto, su arte trasciende las metas científicas de la psicología (1976, pp. 17-18).

Si bien el escritor alemán fue un ser insatisfecho, al mismo tiempo fue una persona con un espíritu autosuficiente. $Y$ como síntesis de su gran crisis, escribiría en su diario de 1925 lo siguiente:

En mí mismo, por tanto, habían de estar el error y desorden, cuando entraba de tal manera en conflicto con el resto del mundo. Y el caso 
es que de hecho sufría un gran desorden. No fue agradable enfrentarme a ese desorden que había en mí y buscarle un sentido. Ante todo quedó clara una cosa: no solo había pagado demasiado caras las buenas relaciones que había vivido con el mundo, sino que ese vivir en paz había sido tan falso como la aparente paz que reinaba la tierra. Había creído que las largas y duras luchas de la juventud me habían valido un lugar en el mundo y que yo era un poeta. Pero, entre tanto, el éxito y la prosperidad habían ejercido su mala influencia, me había dado por satisfecho, apoltronándome, y un examen atento revelaba que el poeta casi no se distinguía de un escritor de amenidades. Me habían ido demasiado bien las cosas. Ahora no me faltaban contrariedades, que son siempre una buena y enérgica escuela, y así fui aprendiendo a dejar que los asuntos del mundo siguiesen su curso y pude ocuparme de la parte que me correspondía en el desconcierto y la culpabilidad generales. Interpretar esta preocupación en base a mis escritos es algo que debo dejar a discreción del lector. $Y$, sin embargo, yo sigo abrigando la secreta esperanza de que con el tiempo mi pueblo también pasará por una prueba parecida, no en su globalidad, sino como un conjunto de muchísimas individualidades despiertas y responsables, y que, en vez de la mala revolución, millones de corazones se preguntarán: ¿habré tenido también mi parte de culpa? Y ¿cómo recuperar la inocencia? Pues siempre se puede recuperar la inocencia, si se admite el mal y la culpa y se sufren hasta el fin, en vez de intentar descargar la culpabilidad sobre otros (1943, p. 16).

Por lo demás, Hermann Hesse es considerado como un guía espiritual por sus lectores, gracias a las obras literarias que escribió a partir de los años de crisis.

Finalmente, en el presente artículo ha quedado demostrado cómo los trastornos psicológicos muchas veces son las génesis fundamentales para la creación artística.

\section{Contribuciones}

Mario Jhonatan Córdova Carruitero ha participado en la concepción del artículo, en la recolección de datos, en la redacción y aprobación de la versión final.

\section{Fuente de financiamiento}

Autofinanciado.

\section{Conflictos de interés}

El autor declara no tener conflicto de interés. 


\section{REFERENCIAS BIBLIOGRÁFICAS}

Ángel, G., Manuel, S. y Ramón, A. (2007). Sigmund Freud: consideraciones sobre la guerra. Revista de Historia de la Psicología, 28(2), pp. 121-127.

Ball, H. (2008). Hermann Hesse. Su vida y su obra. Barcelona: Acantilado.

Bobes, C., Baamonde, G., Cueto, M., Marful, I. y Frechilla, E. (1995). Historia de la teoría literaria. Madrid: Gredos.

Camus, A. (1953). El mito de Sísifo. El hombre rebelde. Buenos Aires: Losada. Hesse, H. (2016). Demian. Madrid: Alianza Editorial.

Hesse, H. (1983). Escritos sobre literatura, 1. Madrid: Alianza Editorial. Horia, V. (1976). Introducción a la literatura del siglo XX. Madrid: Gredos.

Horst, K. (1964). Caracteres y tendencias de la literatura alemana en el siglo $X X$. Múnich: Nymphenburger Verlagshand Lung.

Kierkegaard, S. (2005). La enfermedad mortal. Madrid: Alba Libros.

Michels, V. (1977). Hermann Hesse. Vida y obra en imágenes. Barcelona: Editorial Planeta.

Modern, R. (1995). Historia de la literatura alemana. Ciudad de México: Fondo de Cultura Económica.

Prinz, A. (2002). Y todo comienzo tiene su hechizo. Biografía de Hermann Hesse. Barcelona: Herder.

Serrano, M. (1965). El círculo hermético de Hesse a Jung. Santiago de Chile: Zig-Zag.

Sobrevilla, D. (1977). Introducción a la literatura alemana. Lima: Editorial Universidad Peruana Cayetano Heredia.

Vargas Llosa, M. (1997). Cartas a un joven novelista. Barcelona: Planeta.

Ziolkowski, T. (1976). Las novelas de Hermann Hesse. Madrid: Labor. 